\title{
IDENTIDADE DE GÊNERO NA PRÁTICA PEDAGÓGICA: UMA REFLEXÃO SOBRE O LIVRO "TUDA: UMA HISTÓRIA DE IDENTIDADE"
}

Sayonara Naider Bonfim NOGUEIRA*

Thaís Coutinho de Souza SILVA**

Resumo: O presente artigo apresenta discussões sobre a identidade de gênero no âmbito escolar tendo como objetivo principal descrever uma prática pedagógica autobiográfica desenvolvida no Ensino Fundamental através do livro "Tuda: uma história de identidade" do autor Flávio Brebis, de modo a verificar as contribuições desta prática para uma reflexão sobre as questões de gênero na educação. Especificamente, o estudo buscou também discutir os temas relativos ao preconceito, discriminação, diversidade e padrões de comportamento na escola no que tange às manifestações de sexualidade. A relevância desta pesquisa se justifica pelo fato de que a escola, em sua função social, assinala-se como um espaço democrático que deve oportunizar o debate de questões sociais e permitir o desenvolvimento do pensamento crítico. $\mathrm{O}$ universo escolar é analisado como um dos principais espaços de constituição dos saberes da criança, abrangendo as construções das identidades e, por conseguinte, das diferenças. Portanto, debater as relações de gênero a partir do protagonismo de uma professora transexual é fundamental na legitimação dos debates sobre a diversidade sexual nas instituições de

\footnotetext{
*Especialista em Coordenação Pedagógica pela Universidade Federal de Uberlândia. sayonaratv@hotmail.com
${ }^{* *}$ Doutora em Educação pela Universidade Federal de Uberlândia. thaiscoutinhoss@yahoo.com.br


ensino. Para tanto, na construção do embasamento teórico foram utilizadas a pesquisa bibliográfica e documental. E, para descrever uma prática pedagógica desenvolvida em sala de aula com alunos do Ensino Fundamental valeu-se dos procedimentos técnicos da pesquisa autobiográfica.

Palavras-chave: Identidade de Gênero. Prática Pedagógica. Sexualidade.

Abstract: This article presents discussions about gender identity in the school context, with the main objective of describing an autobiographical pedagogical practice developed in Elementary School through the book "Tuda: a history of identity" author Flávio Brebis, in order to verify the contributions from this practice to a reflection on gender issues in education. Specifically, the study also sought to discuss issues related to prejudice, discrimination, diversity and behavior patterns in school regarding manifestations of sexuality. The relevance of this research is justified by the fact that the school, in its social function, marks itself as a democratic space that should facilitate the debate of social issues and allow the development of critical thinking. The school universe is analyzed as one of the main spaces of constitution of the knowledge of the child, covering the constructions of identities and, therefore, of the differences. Therefore, discussing gender relations based on the role of a transsexual teacher is fundamental in legitimizing debates about sexual diversity in educational institutions. For that, in the construction of the theoretical basis, bibliographical and documentary research were used. And, to describe a pedagogical practice developed in the classroom with students of Elementary School made use of the technical procedures of the autobiographical research.

Keywords: Gender Identity. Pedagogical Practice. Sexuality. 


\section{INTRODUÇÃO}

Trabalhar a questão de Gênero e Diversidade Sexual na escola é o tema proposto neste artigo, a partir de reflexões sobre o livro "Tuda: uma história de identidade". O gênero faz referência à identidade com a qual uma pessoa se identifica ou se autodetermina; independe do sexo e está ligado ao papel que a pessoa apresenta na sociedade e como ele se reconhece. Assim sendo, questiona-se: como o livro "Tuda: uma história de identidade" pode colaborar para o desenvolvimento de práticas pedagógicas e metodológicas que promovam uma educação livre de atitudes e pensamentos preconceituosos?

Sendo a escola corresponsável pela compreensão das relações de gênero na sociedade, teve-se como objetivo geral nesse artigo descrever uma prática pedagógica autobiográfica desenvolvida no Ensino Fundamental através do livro "Tuda: uma história de identidade" do autor Flávio Brebis, de modo a verificar as contribuições desta prática para uma reflexão sobre as questões de gênero na educação. A partir desse objetivo buscou-se também de maneira específica apresentar o Livro "Tuda: uma história de identidade"; discutir as questões relacionadas à discriminação e preconceito, diversidade e identidade de gênero e padrões de comportamento na escola, bem como, analisar o papel da escola na promoção dos direitos 
sexuais dos indivíduos, se tornando um ambiente acolhedor às diferentes manifestações da sexualidade.

Discutir e pesquisar o as relações de gênero a partir do protagonismo de uma professora transexual ${ }^{1}$ é importante e apropriado, pois ajuda a legitimar os debates sobre a diversidade sexual nas instituições de ensino. O livro "Tuda: uma história de identidade" demonstra por meio de suas ilustrações e de uma forma bastante poética e simbólica, conceitos básicos de identidade de gênero, direitos humanos, a importância dos direitos e respeito às diferenças, conteúdos estes que, na maioria das vezes, são pouco trabalhados em sala de aula. Nesse contexto, a escola, em sua função social, assinala-se como um espaço democrático que deve oportunizar o debate de questões sociais e permitir o desenvolvimento do pensamento crítico.

Para embasar as discussões e reflexões trazidas e construídas nesse artigo, inicialmente foram utilizadas as metodologias de pesquisa bibliográfica e documental. E, posteriormente, foi empregada a pesquisa autobiográfica. $\mathrm{O}$ estudo de natureza bibliográfica abrangeu alguns dos diversos teóricos que discutem a temática. Após isso, a partir

\footnotetext{
${ }^{1}$ Refere-se à condição do indivíduo que possui uma identidade de gênero diferente da designada ao nascimento e apresenta uma sensação de desconforto ou impropriedade em relação ao seu sexo anatômico, manifestando o desejo de viver e ser aceito como sendo do sexo oposto.
}

(C) Nogueira; Silva - DiversaPrática, v. 4, n. 1, p. 150-179 - $1^{\circ}$ semestre 2017 
de leitura e fichamento foi possível construir o texto de forma analítica e reflexiva. $\mathrm{Na}$ pesquisa autobiográfica, descreveu-se uma prática pedagógica desenvolvida em sala de aula com alunos do Ensino Fundamental.

Segundo Abrahão (2006), as narrativas autobiográficas podem ser entendidas em seu tríplice aspecto: como fenômeno, como método de investigação e, ainda, como processo de auto formação e de intervenção. Percebe-se que, por meio dessa abordagem, produzimos conhecimentos sobre nós mesmos, sobre os outros e sobre o cotidiano, uma vez que apresentamos as nossas experiências, trazendo-as à luz de teóricos e discussões no sentido de descobrir melhores respostas aos problemas levantados.

Dentre os autores estudados, podem-se destacar os trabalhos realizados por Brebis (2014), Butler (2003), Junqueira (2009), entre outros que apresentam a importância de se trabalhar as questões de gêneros, bem como suas identidades no universo escolar.

\section{DESENVOLVIMENTO}

\section{Diversidade sexual e gênero na escola}

Para Brebis (2014), o livro "Tuda: uma história de identidade" apresenta uma história de identidade que nasceu do encantamento pela 
vida, uma vez que a personagem é um ser que deseja se transformar e se reconhece na sua condição, entretanto, terá que enfrentar grandes desafios durante a sua jornada.

O conceito de gênero significa uma diferenciação, uma vez que a lógica ocidental clássica funciona como uma divisão binária, ou seja, que se decompõe em dois opostos: o masculino e o feminino ou o homem e a mulher. As identidades são particularidades fundamentais da experiência humana, pois permite aos seres humanos a sua construção como sujeitos no mundo social.

Segundo Guimarães (2010), o termo orientação sexual faz referência a como a pessoa se sente em relação à afetividade e sexualidade. Já a identidade de gênero faz menção a como cada um se reconhece dentro dos padrões de gênero constituídos socialmente. De tal modo, não são apenas as características biológicas que definem a construção da identidade de gênero.

Ainda para a autora citada acima, o espaço escolar é analisado como um dos principais ambientes de constituição dos saberes, incluindo as construções das identidades e, por conseguinte, das diferenças. Portanto, a ideia de incorporar o tema às práticas pedagógicas visa propiciar uma discussão para reduzir o preconceito nas escolas e na sala de aula.

Para isso, conforme Guimarães (2010), faz-se imprescindível 
que professores tragam informações e contextualize-as, além de cooperar, oferecendo caminhos para que o educando adquira mais conhecimentos. É também um ambiente de sociabilidade, o que ocasiona na difusão sociocultural, incluindo as relações de gênero.

Discutir sobre gênero está relacionado com a construção de uma cultura que aceita, respeita e incorpora as diferenças sexuais, sejam elas de gênero ou orientação sexual, estabelecendo condições de igual cidadania para todos. Falar sobre gênero e das suas diversas identidades é lutar por uma sociedade onde as oportunidades sejam iguais, reduzindo deste modo as opressões e esse é o papel da educação, para estabelecer um diálogo com a experiência dos educandos.

Refletir sobre gênero é apresentar dados que demonstrem a diferença salarial entre homens e mulheres; entre homens e mulheres de diferentes etnias; de quantas mulheres sofrem violência pela ideia de que os homens podem ser superiores não somente em questão de força, porém economicamente e psicologicamente também; das pessoas travestis e transexuais que não tem espaço em determinados trabalhos e a educação, estando vulneráveis assim a outras violências além das que costuma sofrer no cotidiano. Portanto, essa identidade seria um fenômeno social, e não biológico.

Segundo Junqueira (2009), a escola é um campo de disputas e conflitos importantes, pois se torna o espaço onde se concebe as 
pluralidades de identidades sociais, determinadas e questionadas por diversos movimentos como os feministas, de libertação nacional, os étnico-raciais, os gays, lésbicos e de travestis e transexuais; e todos estes grupos se fazem representar no ambiente escolar e nos currículos que nele se desenvolvem.

Ainda para Junqueira (2009), as transformações no modelo educacional acontecem devido a história, à pressão dos grupos feministas e dos grupos LGBTs que apontaram a invisibilidade e o silenciamento de suas representações de mundo nos currículos escolares. Segundo Braga (2006),

Interrogar a prática pedagógica do professor referente à temática do gênero e sexualidade remete-se ao processo e conjuntura histórica social que desenvolveu a construção de gênero e que se tornou embasamento para repensar a percepção atualizada de sexualidade. Nesse sentido o gênero vai além das visões biológicas, genéticas e morfológicas. A diferença biológica é somente o ponto de partida para a construção social do que é ser homem ou ser mulher (BRAGA, 2006, p.214).

De acordo com Junqueira (2009), a escola brasileira organizouse a partir de um conjunto de valores, preceitos e crenças responsáveis por diminuir à figura do "outro" todos aqueles que não se ajustassem com as referências localizadas no adulto, masculino, branco, heterossexual, burguês, cristão, física e mentalmente "normal". 
Desse modo, Junqueira (2009) aponta que a escola tornou-se um ambiente onde habitualmente circulam preconceitos que põem em movimento discriminações de classe, cor, raça/etnia, sexo, gênero, orientação sexual, crença, capacidade físico-mental etc. Destarte, classicismo, racismo, sexismo e homofobia, entre outros fenômenos discriminatórios, fazem parte do cotidiano escolar como algo diariamente cultivado na escola e que determina efeitos sobre todos os sujeitos sociais.

A escola é um espaço de reprodução e atualização dos parâmetros da heteronormatividade ${ }^{2}$, a qual está no núcleo das concepções curriculares de uma escola comprometida em garantir o sucesso dos processos de heterossexualização obrigatória e de agrupamento das normas de gênero (BUTLER, 2003).

Para Butler (2003), a sociedade constrói mitos, tabus, crenças, preconceitos e representações sobre a sexualidade. Neste contexto, o papel da escola é trazer os conhecimentos que ajudem o jovem a entender e enfrentar os desafios da vida, além de se consubstanciar

\footnotetext{
2 No sentido etimológico da palavra, "hetero" que em Grego quer dizer "diferente" e "norma" que em Latim quer dizer "esquadro", constituem a formação da palavra heteronormatividade, ou seja, um conjunto de ações, relações e situações praticadas entre pessoas de sexos opostos. Assim, toda uma gana de sexo, sexualidade e identidade de gênero deveriam se esquadrar dentro dos moldes da heteronormatividade, sendo esta a única orientação sexual considerada "normal".
} 
como agente precípuo no desenvolvimento da sexualidade nos jovens. É necessário enfocar a sexualidade e a afetividade em uma visão positiva, levando o aluno a perceber que é preciso buscar a qualidade nos relacionamentos afetivos, porém uma busca que ressalte atitudes responsáveis e seguras, que não venham a ferir princípios e valores, o que leva ao respeito ao outro e a si mesmo.

Para Junqueira (2009), a diversidade é pedagógica, e todos tem o direito a uma educação não-sexista, não-homofóbica, não-transfóbica, não-racista e não-classista. Contudo, uma escola que admite e desenvolve preconceitos e que ensina a discriminar não tem como apresentar uma educação inclusiva. Uma escola que reconhece a diversidade e vê como real a expressão da diferença sexual, de gênero e de raça é uma escola melhor para todas as pessoas.

Segundo o autor supracitado, a escola deve propor a condução de um trabalho numa perspectiva capaz de despertar a compreensão de que a sexualidade envolve aspectos que perpassam a questão corporal e considera também a afetividade, as emoções, os sentimentos, as atitudes, as crenças, os valores, e o respeito à diversidade.

A escola e, em especial, a sala de aula, é um espaço distinto para se promover a cultura de reconhecimento da pluralidade das identidades e dos comportamentos referentes às diferenças. Daí, a importância de se debater a educação escolar a partir de uma perspectiva crítica e 
problematizadora, discutir relações de poder, hierarquias sociais opressivas e processos de subalternização ou de exclusão, que as concepções curriculares e as rotinas escolares tendem a conservar (SILVA, 1996).

E mais se devem criar condições para discussão de pontos de vistas diversos, desenvolver a capacidade de criticar e pensar do aluno, erradicar preconceitos, mostrar a sexualidade como algo natural e incentivar nos jovens o respeito pelo corpo e pelos sentimentos. A proposta mencionada é referendada, sobretudo pela necessidade de se trabalhar o protagonismo juvenil, que é um tipo de ação de intervenção no contexto social para responder a problemas reais onde o jovem é sempre o ator principal.

\section{A inclusão de pessoas travestis e transexuais na escola}

Com o desenvolvimento da educação básica no Brasil a partir do princípio da inclusão social, além da atenção oferecida pelos coletivos e organizações sociais LGBT, o tema da exclusão de pessoas transexuais e travestis nas escolas brasileiras principiam nas últimas décadas a tomar contornos, respeitáveis na investigação e na prática educacional. 
Progressos importantes na educação e no movimento de travestis e transexuais foram conquistados. Na educação, em esfera nacional, ocorreu a conquista de importantes espaços no que diz respeito ao reconhecimento e ao direito de usar o nome social desse segmento tão marginalizado; no entanto, ainda procura atenuar os elevados índices de abandono e evasão dessa população nas escolas, devido ao preconceito e a discriminação (REIDEL, 2012, p. 03).

É necessário garantir o acesso e permanência nos bancos escolares, bem como, o respeito imprescindível às diferenças. Ainda deve-se pensar com urgência em uma maneira de vencer a demanda da ausência de escolarização que compromete outras questões de ordem social, como, por exemplo, o trabalho formal.

Percebem-se alguns avanços e encaminhamentos no que tange a inclusão deste segmento no campo educacional. No entanto, até agora, pouco se concretizou na forma de políticas públicas. Para Reidel (2012), existem travestis e transexuais em outros contextos como é o caso de professoras trans, e que, constituíram-se como profissionais da educação no espaço escolar, mesmo diante das inúmeras dificuldades que a profissão apresenta, conseguiram vencer o preconceito gerado pelos colegas professores e por direções de escola.

Conforme Seffner (2005), quando as professoras transexuais e travestis vão para frente de uma turma de alunos, dois aspectos importantes ficam demonstrados: primeiro, que elas são professoras, 
com disciplinas e conteúdos específicos; e segundo que elas são adultos de referência. Independente do fato de ser professora de matemática, artes ou geografia, por exemplo, existem alunos que gostam ou não gostam e que aproveitam para debater as mais diversas questões. Também quanto mais estas professoras assumem e militam, fica claro que ela tem gênero, sexo e uma vida de relações normais e, por isso, se habilitam como adultos de referência na relação ensino aprendizagem. Adultos de referência para todos, incluindo alunos gays e lésbicas. São adultos de referência com uma identidade marcada pela sexualidade, neste caso vista como aquela do enfrentamento, da luta, da conquista de espaços e territórios, como trans, educadora e adulta.

Segundo Junqueira (2009), para que as pessoas travestis ou transexuais apresentem seus direitos de cidadania garantidos, é imprescindível garantir-lhes o direito de serem tratadas em consonância com suas identidades de gênero. O reconhecimento da legitimidade da transgeneridade é categórico para assegurar-lhes autodeterminação de gênero e de dignidade humana. E o que normalmente passa desapercebido é que a transfobia, em todas as suas manifestações, ao renunciar a humanidade das travestis e das transexuais, restringe a humanidade de todos, aprisiona a dignidade de cada pessoa e, na educação, impede o acesso e a permanência das travestis e das transexuais representando um verdadeiro empecilho à consolidação da 
dignidade humana na sua totalidade.

A inclusão de travestis e transexuais dentro do ambiente escolar pode alterar a visão que a sociedade tem desse segmento social, historicamente marginalizado. É o dia a dia que vai fazer a escola transformar e inserir essas pessoas, são tratando-as como sujeitos de direitos, cumpridoras de seus deveres fundamentais para a humanidade e que devem ter o direito de permanecer na sala de aula, como educadoras ou educandas, vivendo um mundo onde o outro e o eu, respeitando as diferenças, sejam capazes de conviver harmonicamente.

\section{O protagonismo de uma professora transexual e sua prática pedagógica a partir do livro: "Tuda: uma história de identidade"}

É importante explicar que a escola não é a principal, nem a única instituição a discorrer sobre sexualidade e debater as questões de gêneros, os meios de comunicação também desempenham uma pressão muito intensa na construção de gêneros, na exibição do corpo e no conhecimento da sexualidade. Imagens dúbias são expostas a todo o momento, desde o consumismo, a valorização da estética e do erotismo, são expostos, para todos os públicos, desde as crianças até os adultos.

Conforme os Parâmetros Curriculares Nacionais (PCNs) de 1998, volume 9, “a orientação sexual deve ter início na infância à idade 
adulta, e sempre existirão perguntas sobre ela, em virtude de estar sempre em construção no gênero". Ou seja, debater os temas transversais no espaço escolar traz um caráter obrigatório e emergencial, sobretudo, para colocar o respeito à identidade de gênero, à orientação e diversidade sexual, bem como a promoção desse respeito no ambiente escolar.

$\mathrm{Na}$ escola onde foi desenvolvida a prática pedagógica em questão, existem vários alunos/as em processo de transição acerca de seus respectivos gêneros, o que gera comentários taxativos por parte de outros educandos. Assim, a proposta da condução do trabalho é numa perspectiva capaz de despertar a compreensão de que gênero envolve aspectos que perpassam a questão corporal, levando em consideração também a afetividade, as emoções, os sentimentos, as atitudes, as crenças, os valores, e o respeito à diversidade.

Várias oficinas pedagógicas foram realizadas, partindo do protagonismo de uma professora transexual da rede pública estadual, o que torna importante e apropriado, pois ajuda a legitimar os debates sobre a diversidade sexual e o combate a transfobia nas instituições de ensino.

O livro "Tuda: uma história de identidade", do autor Flavio Brebis, possui vinte páginas ilustradas, bilíngue (português-inglês), que articula o lúdico a uma crítica da sociedade, propondo o debate sobre a 
diversidade e o respeito às diferenças. A personagem principal não se enquadra nos modelos de gênero e que assevera a diferença, o respeito, a possibilidade de ser feliz sendo você mesmo.

O livro em geral ensina a crianças e jovens, por meio de suas ilustrações e de uma forma bastante poética e simbólica, conceitos básicos de identidade de gênero, direitos humanos, reconhecimento de direitos e respeito às diferenças, conteúdo que tem sido constantemente ignorado nas salas de aula.

Segundo Brebis (2014, p.01), está é "uma história de identidade que nasceu do encantamento pela vida. Tuda é um ser que deseja se transformar e se reconhece na sua condição, mas terá de enfrentar grandes desafios, durante a sua jornada”.

É imprescindível a discussão das identidades de gênero em sala de aula para que as crianças construam um ambiente que mais valorize a diferença e reforce menos estereótipos. "Tuda" é um libelo contra o tradicionalismo e a perpetuação de valores tão retrógrados e que promovem a desvalorização das diferenças de gênero, etnia e culturas.

Flavio Brebis (2014) na obra, ainda brinca com os nomes dos personagens. "Uns e Outros" - são facilmente influenciáveis - e "Nenhum" é um - sacerdote de uma seita religiosa fundamentalista -, ele desaprova “Tuda”. E “Algum” - é o amigo de Tuda - que está com ela nos bons e nos maus momentos. 


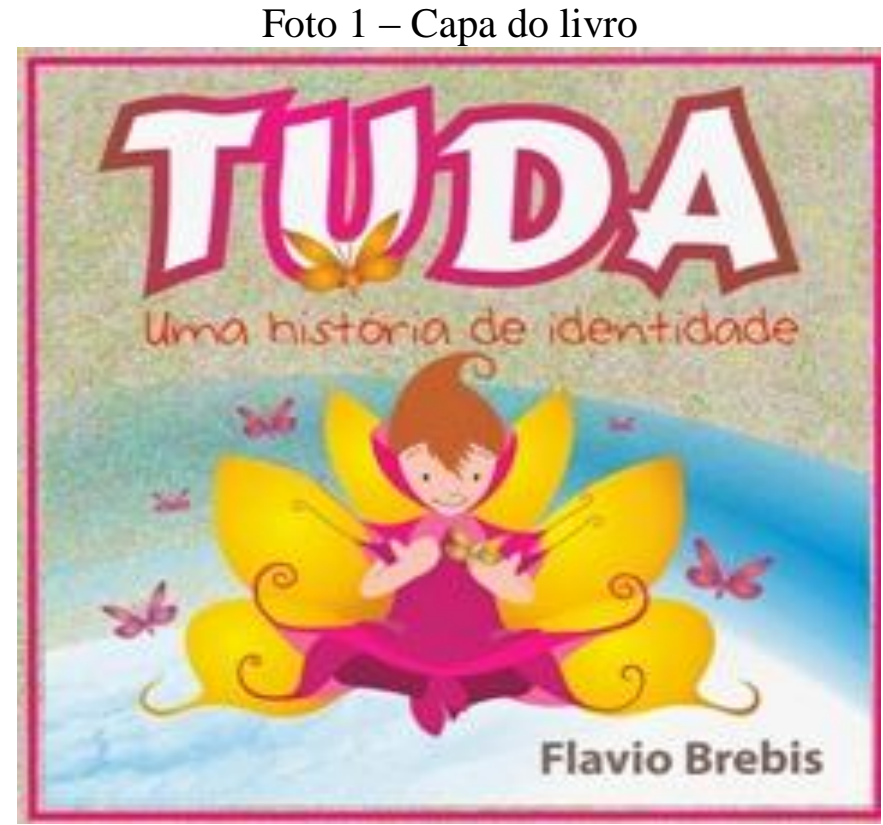

Fonte: Nogueira, Sayonara N. B. (2015).

As oficinas iniciaram-se a partir de uma roda de conversa sobre o conhecimento que os alunos traziam de suas experiências acerca das questões de identidade de gênero e orientação sexual, onde a professora realizou anotações no quadro e explicou alguns conceitos difundidos na sociedade.

Foto 2 - Anotações sobre a roda de conversa 


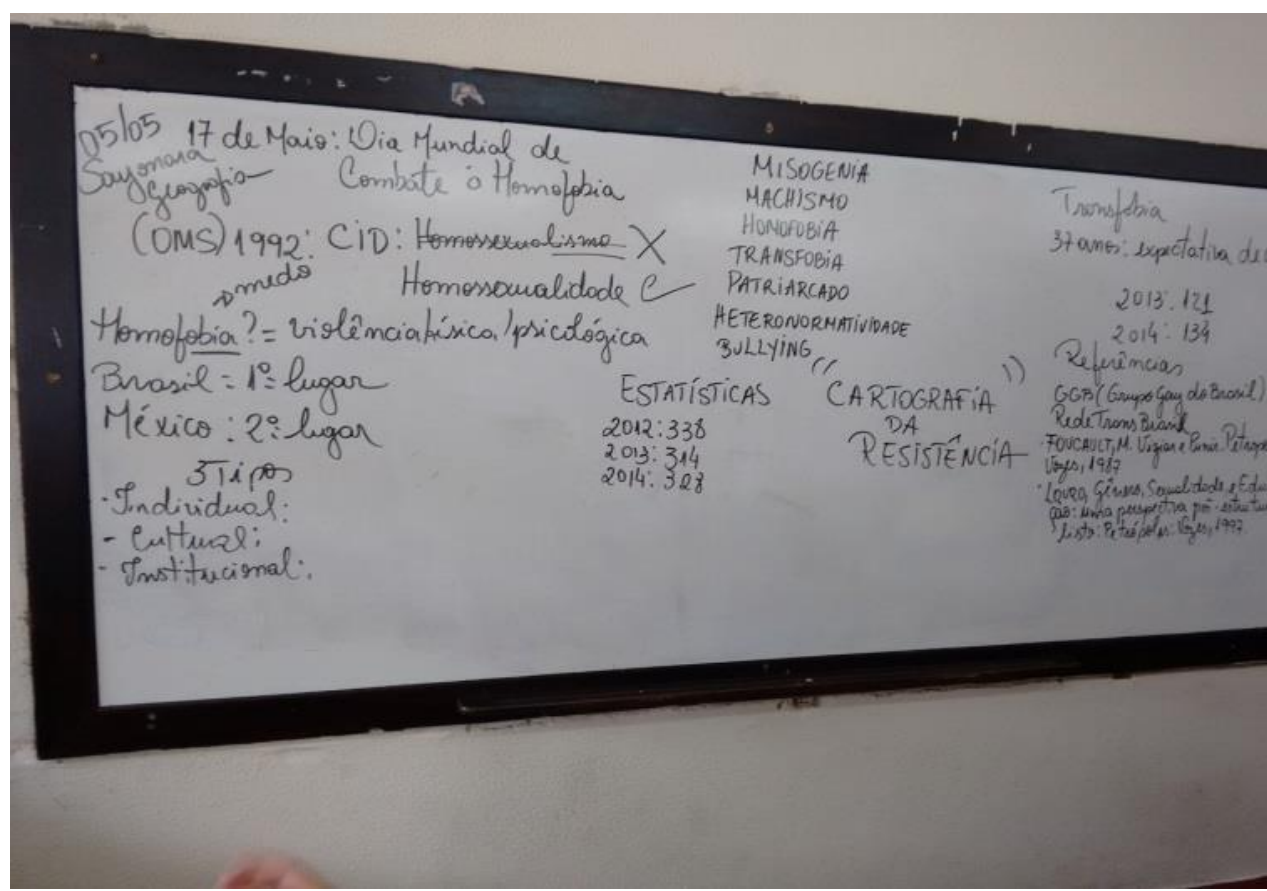

Fonte: Nogueira, Sayonara N. B. (2015).

Posteriormente as essas anotações, as aulas seguiram com a leitura da obra analisada de forma individual e coletiva e seguida de interpretações e transcrição das partes mais importantes ou que chamavam mais atenção dos alunos, e deste modo foram elaborados painéis e apresentados para toda a escola.

Foto 3 - Desenvolvimento das atividades 
Revista Eletrônica da Divisão de Formação Docente (http://www.seer.ufu.br/index.php/diversapratica) v. 4, n.1 - $1^{\circ}$ semestre 2017 ISSN 2317- 0751
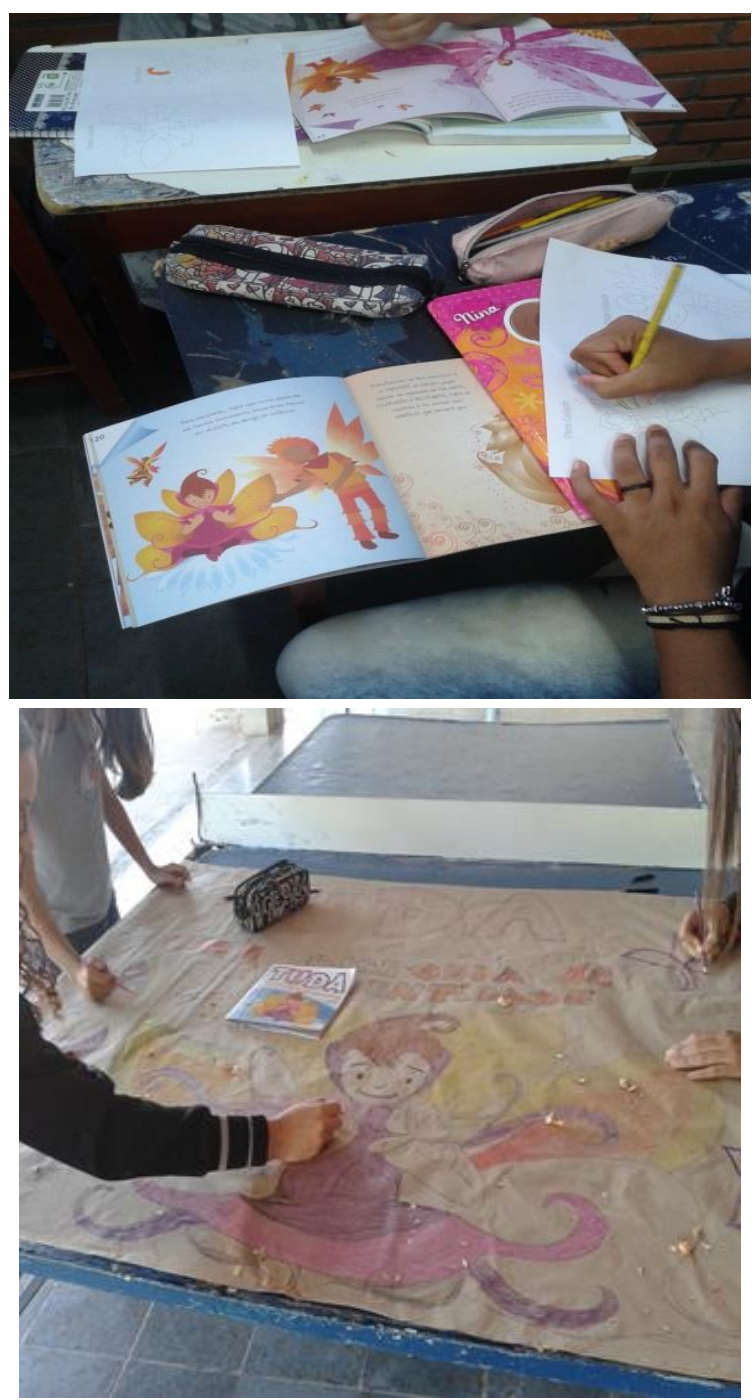

Fonte: Nogueira, Sayonara N. B. (2015) 
Posteriormente ao trabalho com a obra literária, introduziu-se uma atividade baseada na cartografia escolar que compreende conhecimentos e práticas para o ensino de conteúdos gerados da própria cartografia, contudo com conceitos de diferentes áreas.

De acordo com os PCNs (1997), os produtos cartográficos são todos os tipos de documentos: mapas, cartas e plantas em papel ou digital. Esses documentos representam graficamente a superfície da Terra (toda ou parte) e são de grande importância por permitir o entendimento do homem em relação ao espaço geográfico, contudo para tal, é necessária uma alfabetização cartográfica, aprendizado que deve ser possibilitado aos alunos desde as séries iniciais.

O Brasil vive ultimamente um movimento paradigmático em relação aos direitos humanos da população de transexuais, travestis, lésbicas, bissexuais e gays (LGBT). Se por um lado conquistam-se direitos historicamente protegidos, pela grande parcela da população heteronormativa, e se aprofunda o debate público sobre a existência de outras formas de ser e se relacionar afetiva e sexualmente, por outro lado se assiste a aterradora reação dessa mesma parcela heteronormativa em sua vontade de perpetuar o alijamento desses sujeitos e seus afetos (BRASIL, 2012).

O Brasil lidera o ranking de violência transfóbica e no mundo é o país onde ocorrem mais assassinatos de travestis e transexuais. $\mathrm{O}$ 
número de travestis e transexuais que são assassinadas pode ser ainda maior, pois de acordo com o Grupo Gay da Bahia (GGB), que há três décadas realiza o levantamento desse tipo de crime no país, os crimes contra pessoas trans são subnotificados. Em geral, são contabilizados como mortes de homossexuais, inviabilizando políticas públicas e visibilidade social (NOGUEIRA, 2015).

Entre 2011 e 2014, a Ouvidoria Nacional de Direitos Humanos recebeu 7.694 denúncias de violência contra a população LGBT. Destas, cerca de $20 \%$ foram de ocorrências contra travestis e transexuais. Entre os tipos de violações, a discriminação e a violência psicológica estão entre as mais frequentes em 2014, com 85\% dos casos denunciados (NOGUEIRA, 2015).

Em 2013 no Brasil foram 121 pessoas trans assassinadas (dados noticiados e confirmados), onze pessoas não confirmadas (o que elevaria para 132 pessoas trans assassinadas). Sabendo-se que existem muitos casos não noticiados ou informados erroneamente como "homem” ou "homossexual", esses números aqui mostrados ainda não correspondem à realidade que pode ser e é bem pior. Em 2014 foram contabilizados 134 assassinatos de pessoas trans no Brasil (GGB, 2014 apud NOGUEIRA, 2015).

E mais, a expectativa de vida de uma travesti e transexual brasileira gira em torno dos 37 anos, enquanto que, em média, a 
expectativa de vida de um brasileiro é 74,6 anos de idade, segundo Instituto Brasileiro de Geografia e Estatística (IBGE). A partir dessas informações os alunos construíram gráficos e mapas demostrando de forma estatística o índice de violência que as pessoas travestis e transexuais são acometidas no país.

Houve uma grande dificuldade na busca de artigos e sobretudo, matérias relacionadas ao universo da transexualidade e da travestilidade, segundo os alunos, pois muitas pesquisas acadêmicas ainda se referem a construção dos corpos dessa população, a questão da vulnerabilidade do HIV/AIDS, a prostituição e recentemente alguns estudos sobre o trabalho de professores/as travestis e transexuais no campo escolar.

Foto 4 - Desenvolvimento das atividades 
Revista Eletrônica da Divisão de Formação Docente

(http://www.seer.ufu.br/index.php/diversapratica) v. 4, n.1 - $1^{\circ}$ semestre 2017 ISSN 2317- 0751
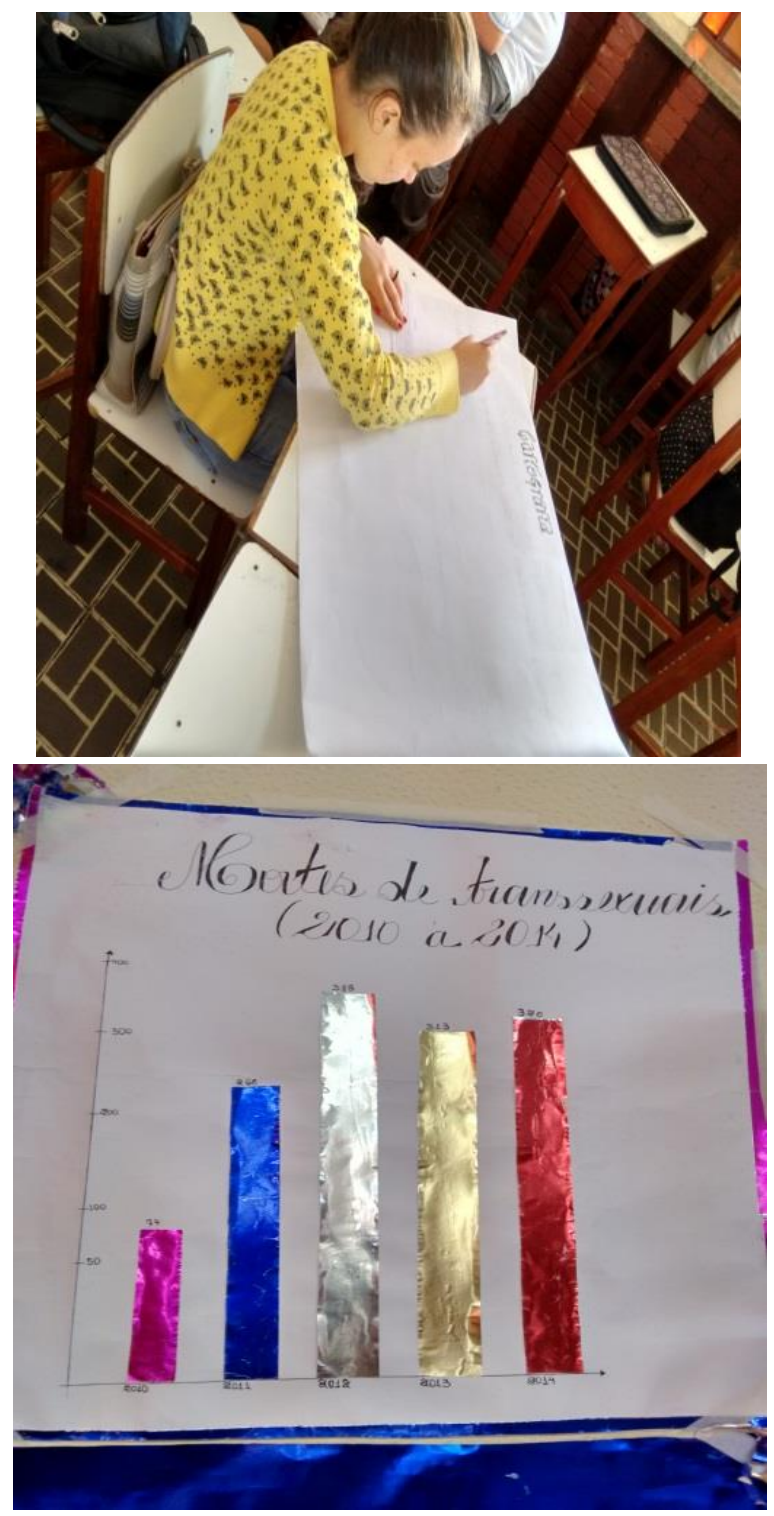

Fonte: Nogueira, Sayonara N. B. (2015). 
Revista Eletrônica da Divisão de Formação Docente

(http://www.seer.ufu.br/index.php/diversapratica) v. 4, n.1 - $1^{\circ}$ semestre 2017

ISSN 2317- 0751

Foto 6 - Painel com as atividades desenvolvidas

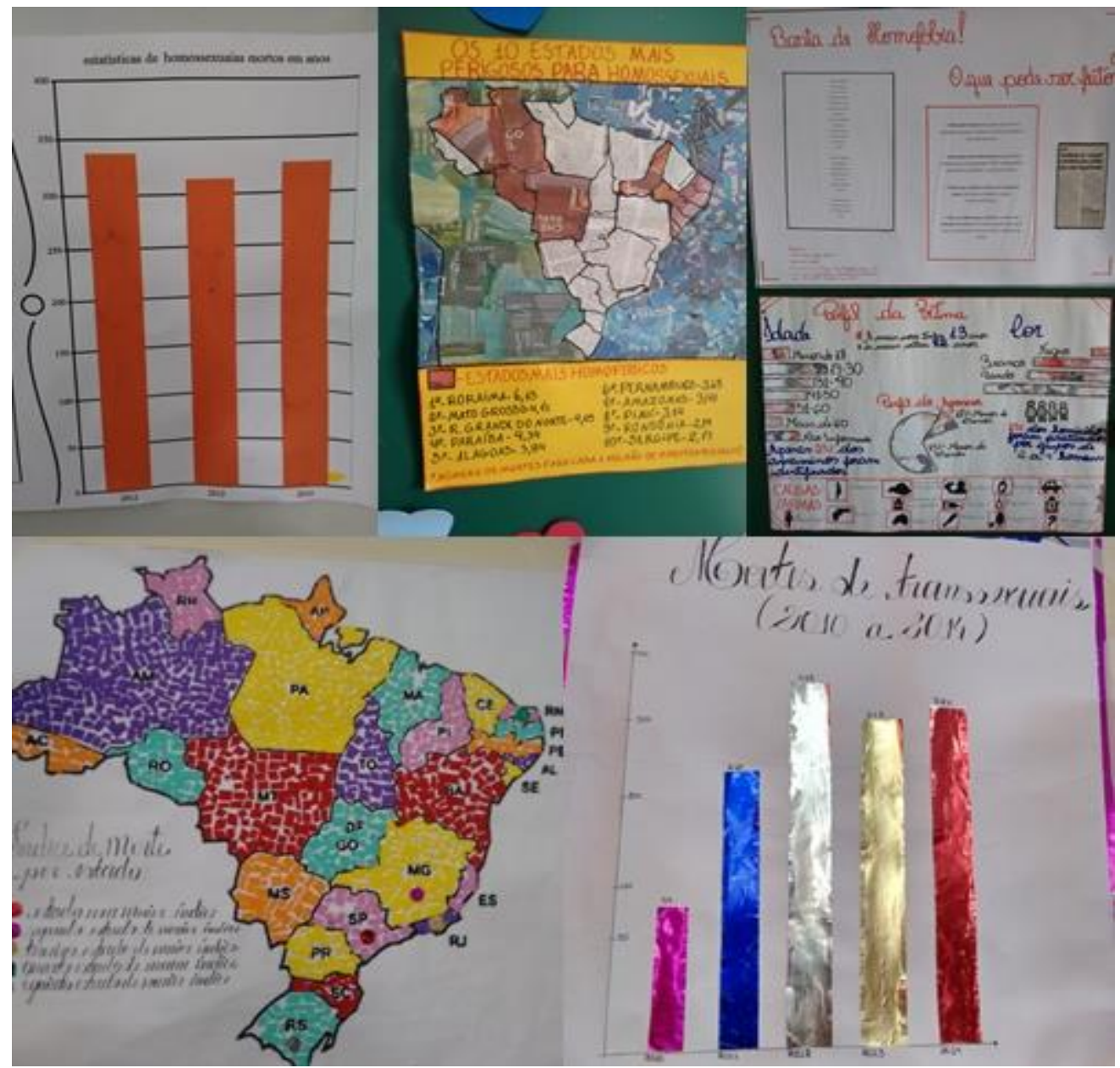

Fonte: Nogueira, Sayonara N. B. (2015).

(C) Nogueira; Silva - DiversaPrática, v. 4, n. 1, p. 150-179 - $1^{\circ}$ semestre 2017 
Como conclusão do trabalho, os alunos chegaram a seguinte reflexão, de que hoje a maioria esmagadora das pessoas travestis e transexuais que se encontram nas ruas, em condição de prostituição, devem-se ao fato da exclusão social que esses sujeitos sofrem, onde a família e a sociedade expulsa e marginaliza, e a escola, por sua vez, torna-se um motor de exclusão. Os alunos concluíram ainda, que falta no país uma política de identidade de gênero e de políticas políticas públicas de mercado de trabalho e geração de renda para essa população.

\section{CONSIDERAÇÕES FINAIS}

A Carta Magna brasileira, promulgada em 1988, em seu artigo 6, institui que a educação é um direito de todas e todos e, ainda, que condições para o acesso e permanência escolar devem ser garantidas pelo Estado. Contudo, pesquisas científicas vindas dos mais diferentes campos disciplinares evidenciam que grupos específicos da população são sucessivamente afastados da escola.

A extensa gama de diversidade cultural, sexual, social, étnicoracial, entre outras, está presente no ambiente escolar e necessita descobrir maneiras de lidar com as diferenças sem que elas se transformem em motivos de preconceito ou discriminação. Pessoas de 
orientações sexuais e identidades de gênero diferentes frequentam a escola e precisam trazer sua sexualidade e suas identidades respeitadas, uma vez que torna-se um exercício de cidadania.

Se os educadores não lançarem mão de suas competências pedagógicas e didáticas para lidar com esta questão, a escola e seus profissionais continuarão legitimando o preconceito, a discriminação, as hierarquias de gênero e a violência transfóbica nas escolas.

O universo escolar é analisado como um dos principais espaços de constituição dos saberes da criança, abrangendo as construções das identidades e, por conseguinte, das diferenças. Portanto, a ideia de coligar o tema ao Projeto Político-Pedagógico da escola objetiva propiciar um debate para atenuar o preconceito nas escolas, além de dispor as instituições de ensino para combater a discriminação de identidade de gênero.

Faz-se imprescindível introduzir propostas pedagógicas com conteúdos sobre sexualidade, diversidade quanto à orientação sexual, relações e identidade de gênero, pela necessidade de constituir formas de impedir a evasão escolar determinada pela identidade de gênero. Somente por meio da educação de qualidade, da transformação e flexibilidade dos currículos escolares, nesse caso, a introdução dos diálogos sobre gênero e diversidade sexual, é que teremos no futuro uma sociedade menos preconceituosa e mais tolerante. 


\section{REFERÊNCIAS}

ABRAHÃO, Maria Helena Menna Barreto (Orgs.). Tempos, Narrativas e Ficções: a invenção de si. Porto Alegre: EDPUCRS; Salvador: EDUNEB, 2006.

BRAGA, E. R. M. A Questão do gênero e da sexualidade na educação. In: RODRIGUES, Elaine e ROSIN, Sheila Maria. Infância e práticas educativas. Maringá-Pr: EDUEM, 2007. p. 211-220.

BRASIL. Secretaria de Direitos Humanos. Relatório sobre violência homofóbica no Brasil: ano de 2012. Disponível em:

$<$ http://www.sdh.gov.br/assuntos/lgbt/pdf/relatorio-violenciahomofobica-ano-2012>. Acesso em 21 out. 2015.

BRASIL. Secretaria de Educação Fundamental. Parâmetros Curriculares Nacionais: Geografia. Brasília, MEC/ SEF, 1998.

BRASIL. Ministério da Educação. Secretaria de Educação Fundamental. Parâmetros Curriculares Nacionais: pluralidade cultural, orientação sexual. Brasília, DF: MEC/SEF, 1997.

BREVIS, Flávio. Tuda: uma história de identidade. Brasília, 2014. 
BUTLER, J. Problemas de gênero. Rio de Janeiro: Civilização Brasileira, 2003.

GUIMARÃES, Letícia de Castro. Relações de gênero e sexualidade: estudo sobre as relações de gênero e as contribuições da prática docente para a desmistificação de diferenças e preconceitos em relação ao sexo (sexismo) em sala de aula. Monografia (Graduação), Universidade Federal do Maranhão, Centro de Ciências Sociais, Faculdade de Pedagogia, São Luís, 2010.

JUNQUEIRA, R. (Org.). Diversidade sexual na educação. Brasília: MEC, 2009.

NOGUEIRA, Sayonara N. B. Cine Debate: Transexualidade e Travestilidade no Mercado de Trabalho. Programa 'Enactus', Instituto de Economia (IEUFU) da Universidade Federal de Uberlândia, 2015.

REIDEL, Marina. Educadoras Travestis e Transexuais na Escola Pública Brasileira: nem tias, mães, ou professorinhas, mas adultos de referência. In. Anais VI Congresso Internacional de Estudos sobre a Diversidade Sexual e de Gênero, Salvador, 2012.

SEFFNER, F. Identidades Culturais. In: Revista do professor, Rio Pardo/RS, v. 21, n. 83, p. 20-24, 2005. Disponível em: <http://www.viavale.com.br/cpoec>. Acesso em 10 ago. 2015. 
SILVA, Tomaz Tadeu da (Org.). Identidades terminais: as transformações na política da pedagogia e na pedagogia da política. Petrópolis: Vozes, 1996. 